
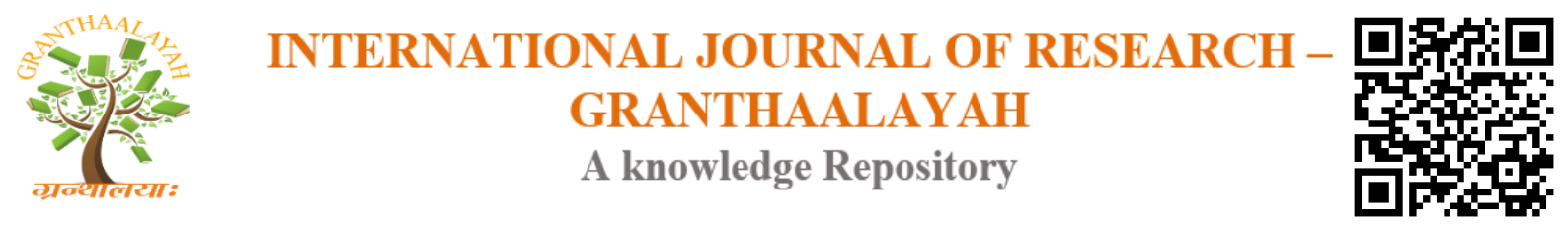

Social

\title{
TEACHERS' RESILIENCE: A CHALLENGE OF COMMITMENT AND EFFECTIVENESS
}

\author{
Teresita Villa G. Lacaba, D.M. ${ }^{1}$, Alvin B. Lacaba, Ed.D. ${ }^{2}$, Mamerto A. Caliwan, Jr. ${ }^{3}$ \\ ${ }^{1,2,3}$ Eastern Samar State University Guiuan Campus, Guiuan, Eastern Samar, Philippines
}

\begin{abstract}
Teaching is an emotionally demanding work. To teach, and to teach at one's best over time, has always required resilience, otherwise conflict within the self and classroom routine will set in. Anchored on the theories of resilience, motivation, self-determination, personal values, and capability approach, this case study will describe on the consequences of teachers' resilience on its commitment and effectiveness to teaching. Eight teachers of the Department of Education assigned in island schools in Guiuan, Eastern Samar will comprise as the participants. Data generated through in-depth interview, using a semi-structured interview guide will be used and will be kept strictly confidential. Data generated from the participants will be transmitted verbatim, in-vivo coded and will be compared and contrasted with previous research and theory based literature for triangulation of findings that will add to the body of knowledge and directions for future research activities.
\end{abstract}

Keywords: Teaching; Teachers; Teachers' Resilience; Resilience; Commitment; Efficiency.

Cite This Article: Teresita Villa G. Lacaba, D.M., Alvin B. Lacaba, Ed.D., and Mamerto A. Caliwan, Jr.. (2020). "TEACHERS' RESILIENCE: A CHALLENGE OF COMMITMENT AND EFFECTIVENESS.” International Journal of Research - Granthaalayah, 8(4), 79-88. https://doi.org/10.29121/granthaalayah.v8.i4.2020.10.

\section{Introduction}

Teaching is emotionally a demanding work. To teach, and to teach at one's best over time, has always required resilience. Teachers who face and struggle with many difficulties in their professional life, need their resilience to be at high level. Teaching is a profession members of which are confronted with many situations that generate stress and conflict. Teachers are expected to continue their work efficiently despite everything (Bayrak,2004). Teacher efficacy has been receiving mushrooming attention for the past two decades in the field of Teacher Education. Resilience, the ability to withstand difficulty and bounce back is among those features that closely appertain to the fast growing province of teacher efficacy (Day \& Gu, 2007; Howard \& Johnson, 2004). This case study explored resilience of teachers assigned in island schools 
The notion of resilience originated in the disciplines psychiatry and development psychology as a result of a burgeoning attention to personal characteristics or traits that enabled some children, to adapt positively and thrive despite significant adversity (Waller, 2001). Henderson and Milstein (2003) see a resilient teacher as one who gives of self in service to others and/or cause, uses life skills, including good decision making, assertiveness, impulse control, and problem, solving, and one who has: ability to be a friend, ability to form positive relationships, sense of humor, selfdiscipline, positive view of personal future, flexibility, capacity for and connection to learning, personal competence, self-motivation, and feelings of self-worth and self-confidence.

In the context of the teaching profession, resilience may be conceptualized as a capacity, a process and also as an outcome. Resilience involves the capacity of an individual teacher to harness personal and contextual resources to navigate through challenges, the dynamic process whereby characteristics of individual teachers and of their personal and professional contexts interact over time as teachers use particular strategies, to enable the outcome of a teacher who experiences professional engagement and growth, commitment, enthusiasm, satisfaction, and wellbeing (Beltman, 2015).

The term 'resilience' or 'resilient' has become commonly used in everyday language and so it is important to clarify what 'resilience' means in the context of the teaching profession. Early definitions of resilience focused on identifying the particular risk and protective factors that enabled or constrained resilience and particular traits that characterized resilient individuals. Definitions of resilience have included not just recovery from stress to a previous level of health but of sustained growth as a result of a healthy response to stressful situations (Reich, Zautra, \& Hall, 2010).

The theory of self-determination (Deci \& Ryan as cited by Tan, 2014) contends that a person must be in control of one's life, relate with conditions around, and eatablish bonds and tie-ups. This theory further contends that the kind of motivation needed for the fulfillment of a person's need or goal can either be internal or external to the self that initiates, presses, or coerces one's action. IN relation to the study, this theory assumes that a financially vulnerable teacher with internal perceived locus of causality initiates and sustains own actions and is self-determined because his/her behavior stems from own choice or priority. On the other hand, when the financially vulnerable teacher has an external locus of causality, he/she considers behavior as being controlled by some external situations, event, persons, or force. To discover the perceived locus of causality in relation to setting and achieving goals and priorities of the financially vulnerable teachers is a reason d'etre for the conduct of the study.

\section{Methodology}

\section{Research Design}

Case study was the research design used to explore the resilience of teachers and its challenges to commitment and effectiveness to teaching. Case study is an approach to qualitative research that facilitates the exploration of a phenomenon within its context using a variety of data sources. It ensures that the issue is not explored through one lens but rather a variety of lenses but rather a variety of lenses which allows for multiple facets of the phenomenon to be revealed and understood 
(Baxter \& Jack,2008, p. 544). It is an in-depth examination of a particular case or several cases (Lichtman, 2013, as cited in Wa-Mbaleka, 2016).

\section{Research Instrument}

The study utilized a research-made and expert-validated semi structured interview guide written in English, composed of 14 items; 4 were specific questions about teachers resilience and its consequences to commitment and effectiveness of teachers.. A senior faculty with wider research experience offered suggestions in improving the interview guide, in which items therein where based on literature topics connected to the study, and the same interview guide was utilized in generating information from the participants through personal interview. A test-run of the interview guide was done with the teachers from the island schools to ascertain whether or not the items in the interview guide were closely understood by the interviewee and likewise ascertain that the data generated from the interview were the needed data for the study. Reactions of the interviewee and other important observations endemic to the personal interview were noted as inputs during the interview of the research participants.

\section{Sampling and Research Setting}

The selection of the participants was purposive. This means that the participants meet the following selection criteria: a) classroom teacher of the Department of Education whose work assignment is in an island school in Guiuan Eastern Samar. Hence, the personal information of the prospective teacher participant to be taken from the records of the school.

\section{Data Collection and Ethical Considerations}

To be able to conduct the study, the research proposal will be presented for comments, suggestions and approval by the Research Technical Working Committee of the university during the research proposal hearing. A letter request to conduct a face-to-face interview with the target teacherparticipants will be solicited from respective school heads (Appendix B). A ready-made informed consent (Appendix C) will be presented to the participant to solicit voluntary participation with the assurance that any verbal or written information elicited during the personal interview will be treated confidential and will be solely realized for the study.

With the use of the interview guide (Appendix A), the face-to-face or personal interview will be done in English language. Occasional use of Waray or the native tongue will be made during the interview to create a casual or ordinary mode of conversation. Asking of probing questions will be made to establish certainty of information. The date that will be elicited from the interview will be saved in a mobile phone, with due permission from the participants. To maintain confidentiality, the participants will be coded as either Participant 1, Participant 2, up to Participant 8. The number as suffix to each participant will represent the sequence of the interview with them.

\section{Data Analysis}

Analysis of data will be done immediately after its verbatim transcription. Data will be transcribed as captured by the mobile phone recorder. In vivo coding (Saldana, 2015) will be adapted to keep the participants' own language. The diverse data available in sentence codes will be linked to the group of ideas or categories. The themes will evolve based on analytic reflections from the codes and categories. In the analysis, sparring vernacular terms will be assigned with the closest English terminology. All data will be analyzed in conjunction with presentation of the answers to research 
questions, and in reference with the organization of information significant in defining the conclusions and recommendations.

- How the research subjects or samples were selected should be discussed

- How interviews, and other qualitative data collection methods (how such were carried out for example) should be mentioned

- How the researchers handled data and interpreted them should be mentioned and discussed thoroughly anchored from the theoretical and operational frameworks/models of the study

\section{Findings}

\section{Results and Discussion}

The result of this study is presented based on the individual research questions. The findings suggest the following. First, the island teachers have shared experiences regarding the challenges pertinent to their workplace. Second, these manifest challenges reinforced the buildup of teachers' resiliency among the island teachers. Third, the acquired resiliency of the participants significantly contributed to their motivation and effectiveness in teaching.

\section{Theme 1: Shared Challenges in the Workplace}

In their narratives, the participants conveyed their shared struggles being teachers destined in the island. It should be noted that all the participants were born and raised in the mainland thus, devoid of concrete grasp of the lifeworld in the island, except the fact that getting there is a bit risky. But confronted with otherwise than to secure a job, they have to admit the workplace. Except for the two teachers who were recently assinged in San Juan Elementary School, Tubabao Island - both are just more than a year - the other three participants have been there for a number of years. The longest stay is about twenty nine (29) years of teaching particularly in Camparang Elementary School, Tubabao Island.

In the thematic analysis of the transcribed data, the researchers identified three (3) manifest challenges disclosed by the participants in relation to their workplaces specifically, (1) The Stakeholders, (2) The Transportation, and (3) The Weather Condition. To be precise, these factors are duly regarded by the island teachers as causes of anxiety on their part.

First, at a certain extent, all of the participants reported their disconcerts in handling their stakeholders, in particular, the pupils and some parents. On the one hand, evident in the responses of the teachers are the issues on the pupils' behaviour.

Participant 1: "That's it... their being noisy...sometimes they are brawling... their being childish."

Participant 2: "Not all are polite. There are also naughty pupils... who fight back to their teachers."

Merc and Subasi (2015) indicated that the disruptive behavior of the students in the classroom is notably one of the headaches of the teachers. Moreover, the participants likewise complain about the disinterest and low performance of some pupils which resulted frustration to the former. When asked about the probable cause of such disposition, the participants blamed it to the livehood activity of the family. 
Particpant 5: "Everytime I asked them, they would say that they went fishing last night."

On the other hand, some of the parents are not supportive to the education of their children. Without prejudice to some who really backup their pupils and are active in every school activities, there are parents who do not even supervise the school activities of their children such as homework, assignments, project and the like. Worst, some would even convince their pupils to work than to study.

Participant 4: "Some parents do not follow up their children. It seems that they leave all the obligations to us teachers."

Based on the narratives of the teachers, some parents in the island do not yet see the value of proper education. They would rather let their children venture the labor market than educate themselves first in the classroom. Although this observation does not entails a sweeping assumption - this is distinct to particular barangay, and not all informants shared the same - nonetheless, since such mindset exist, it thus challenges the perspective of the teachers destined in the island.

Second, the transportation is but another obstacle that test the commitment of the island teachers. The means of transport of the participants is not as easy as in the mainland whereby schools are accessible any time of the day. Hence, this event creates a challenge on their time management. According the participants, they really have to adjust their time by waking up earlier than usual in order to make the necessary preparation in their individual households, - especially that three of the participants have families to attend to - to catch the boat that will ferry them to the island, and of course, to arrive to their respective schools on time.

Participant 2: "I have to wake up very early. But sometimes, we still have a problem because sometimes the driver of the boat has other business in the market. So we have to wait."

Aside from managing their time, the participants conceded their inconveniences in accomplishing some urgent errands that would prompt them to cross the mainland since the boats are not always available; and if it is, for sure it will not propel them unless a considerable number of passengers are aboard. Otherwise, they have to hire the boat and compensate the boatman accordingly.

Another thing, the participants admitted their financial concerns, particularly with regard to their transportation expenses. Two of the participants said that a big portion of their salaries are sliced for their daily transportation allowance, especially that the boat fare is not fixed. It depends on the time of the day and the condition of the weather.

Participant 3: "If the weather is bad, the boatman would charge us with higher fare. And we cannot but agree since we want to go home."

Participant 4; "Kun nagdadagmit ka, tapus alanganin it oras, mapipiritan ka talaga magpakyaw nala, kay d man malakat nga usa kala."

Third, all the participants concurred that their greatest challenge is the rough weather condition. As mentioned earlier, none of them had dwell in the island thus crossing the troubled seas is 
undeniably fearsome to them. This circumstance confronts the island teacher every day of their lives considering that the participants opted not to rent a house or any accommodation in the place but go home every after work.

Participant 3: "Crossing the sea to get to the school, and cross again after work...it's really distressful... especially if the weather is bad."

Participant 1: "If the weather is really bad... that's our biggest problem. Of course, we to have to make sacrifice. Still we have to consider our pupils in the island."

Evident in their significant narratives, the participants' commitment to their profession is tested by stormy weather, and that, despite of such event still, they have to cross the rough seas because their clients, the pupils, wait for them on the other side. This scene frequents the island teachers most particularly in the months of December, January and February whereby the Amihan wind is bothering the seas. Though they consider some thoughts of not going to school, especially during these times, due to the risk of the bad weather, but their consciences are telling them that someone else's future count on them beyond the troubled waters.

In their interviews, all the participants coincided with this three main consequential challenges of being an island teacher - although there are other problems such as lack of school budget, lack of teachers, conflicts with family obligations and the like. They admitted their anxieties and dismay however, as their words go: "We can't do otherwise, we need a job and this is our job," they have to withstand amidst these challenges because definitely their living bank on their being teachers. Over and above, they have made a commitment of educating the youth.

\section{Theme 2: Teachers' Resiliency Buildup}

The second theme which emerged through the explication and data analysis is the buildup of the teachers' resiliency. This part shed light to the second research question of the study, that is, "How did the participants develop teachers' resiliency in the workplace?" Proceeded from their in-depth interviews, there are three (3) sub-existing themes that transpired such as: (1) Teaching as Livelihood, (2) Teaching as Duty, and (3) The Community Relations.

On the hand, all the participants confessed that they happened to become teachers because it was the least viable option - education courses are being offered in the locality with a minimal tuition fee - however, it is considered as one of the promising and secured job. According to two of the participants, education was not their desired course, however due to lack of financial security they were leave with no choice than to pursue it. Besides, another teacher informed that, during their time, it was the only available course to fit women. As the case of the participants, having no choice of their own, teaching became a choice. Thus, given the opportunity of becoming a regular public teacher, they catch hold of it without considering their assignments.

For this reason, one thing that triggered the island teachers to unroll their resiliency is the context of making a living. When asked about their motivation of keeping their profession, their answers always meet the bottom-line, that is, their livelihood.

Participant 4: "uhmm ... the salary (laughing)... it's the source of our income..." 
Participant 5: "I ready myself... sometimes I feel afraid but I have pursue because as they say, this is our livelihood...(laugh)"

Correspondingly, the participants convinced themselves to stay strong amidst the manifest dilemmas in the workplace for their own sake and their family as well. As repeatedly said in their interviews: "We need to face it," the participants cannot but be resilient inasmuch as they have continue making a living. Thus teachers' resiliency is a necessary experience in the case of island teachers.

On the other hand, the participants have likewise emphasized that teaching is primarily a duty. As reported, teachers have to be committed to their work since it would be the pupils' disadvantage whenever the former would cede due to some inconveniences. That is why more often than not, the participants regard teaching more of a duty than a career.

Participant 1: "There are times that we tremble in fear... some would cry... but you know, it is our duty."

Participant 3: "We really have to... we have to persist because of our pupils. Although the waves are huge, we have get there."

Evident in their weighty narratives, another thing that reinforced teachers' resiliency of the participants is the call of duty. Indeed, there is eminent danger in their work, but according to them: "As long as the boatman said they could sail, then they would sail." In the interviews, the island teachers narrated their most frightening experiences crossing the rough seas. Some of the stories were straightforward, while others were humorously recounted, nonetheless, the crux is that they have conquer their fears because their duty look forward to them across the mainland.

Participant: 1: "There was a time that we were not able to go home because of the storm. The boatman told us that it was already dangerous to sail. That's why, we were forced to sleep in the school."

As revealed in this study, the sense of duty impels the island teachers to develop resiliency. Again, teaching is not just a job but more of a duty. This perspective hoovers in the accounts of the participants. Thus, teachers' resiliency, at a certain extent, is rooted in their concept of their job. As the case of island teachers, teaching is viewed as duty.

Lastly, the workplace has a counterpart in the buildup of teachers' resiliency. It should be noted that the latter is not solely a product of one's determination and sense of duty, but further compounded and sustained by some factors relevant to the former (Gu and Day, 2013). In this case study, another thing that scaffolds the resiliency of the participants is the community relations existing in the place.

First, the participants conveyed their good relationship with their pupils. Accordingly, the constant contact of the participants with their pupils lead them to develop a sense of affinity that in the long run, persuade the former to stay despite of the unrelenting risks mentioned above. 
Participant 4: "Although sometimes my pupils are stubborn and misbehaving, still I care for them. And it makes me so happy knowing that they learn in me."

Participant 2: "It's the pupils...sometime I consider to transfer but I think my pupils need me. So I rather stay... Bahala na!”

Second, the participants likewise highlighted the positive relationship between the school administration and the local community. They mentioned the supportive attitude of the parents as well as the barangay officials.

Participant 1: "The whole community are very supportive. Every time we call for meetings, they always attend without reservation. That's why I really choose to stay though there already opportunities for me to transfer to the mainland."

Considering that there are participants who lasted as long as 29 years in the island, the researchers asked some probing questions to reconcile their prolonged stay with their confessed anxieties. Based on the responses, the researchers come up with a grounded understanding of the underlying cause that made the island teachers sustained their stay for several years again despite of the aforementioned inconveniences, that is positive relationship and mutual support in the community. Participant 5: "My first assignment is in the island, and I believe it will also my last since I am about to retire... (laughing)."

\section{Theme 3: The Impact of Resiliency to Teachers' Commitment and Effectiveness}

The last theme that emerged in the thematic analysis is the impact of resiliency to teachers' motivation and effectiveness in teaching particularly to the island teachers. This section best answer the third research question presented above.

Gu and Day (2006) suggested the teachers' effectiveness could be measured through the improvements in students' progress. In consonance with this, some of the participants stated their pertinent achievements in their profession.

Participants 2: "I am happy that some pupils in the island are now competing with other pupils in a distinguished contest... and sometimes they top the competition (laughing)."

Participant 5: "Before, there were many drop outs and out-of-school-youth in San Juan, (Tubabao). What I did... I conducted regular home visitation, convincing the parents and encouraging the children to enroll... and you know what, every year I abled to produce graduates. In fact, before my time, San Juan was just a primary school but, it is already a recognize Elementary School by now."

Evident in their significant achievements, are likewise the manifestation of their improved commitment and effectiveness in the field of education. As they shared their experiences of teaching in the island, they are convinced about their notable growth in their profession. According to them, being assigned in the island would really transformed a teacher in order to adapt the prevailing context. Furthermore, they believe that no single island teacher could be less committed to teach given their true-to-life experiences. 
Participant 1: "If you are brave and strong enough, you will survive like the way I survived (laughing). But of course, you must be committed (laughing)...I am about to retire...."

Participant 4: "If you commit yourself to your work, you would survive no matter what."

In this study, it was revealed that the commitment and effectiveness of island teachers are primarily measured according to their ability to perform their task - commitment and effectiveness -, second, may be, though not necessarily due to some existing culture of the place, through the improvement and progress of their constituents. On the one hand, the very fact that teachers sustained their daily routine of going back and forth to the island, facing the risk of circumstantial rough weather, and still manage to perform their task, is already a concrete manifestation of strong commitment and effectiveness. Otherwise they would eventually seek for transfer of worst, give up teaching.

As one the participants said: "Even now, if we encounter bad weather, I still tremble in fear, but I have to face it," this only suggest, that the challenge of traversing the workplace due inclement weather condition is a persisting test to their resiliency nonetheless, when asked why still survive in such condition, their commitment would be the sum and substance of their endeavor. Following their logic, "If a teacher is surviving the challenge in the island, there is no way to questions his or her commitment and effectiveness. Because if they are not, they would give up sooner than later." Thus, as the case of the island teachers, resiliency is but an offshoot of combined commitment and effectiveness in the teaching profession.

\section{Discussions}

1) Should stick to a discussion of the findings. The researcher now gives opinions or critiques to the findings or discoveries

2) Never stray discussions beyond data gathered

\section{Conclusions}

Base on the findings, the following recommendations were drawn.

- Since the community relations significantly contributes to the resiliency of the teachers, it is therefore recommended that the school administration should see to it that there is a supportive attitude and mutual relationship between and among the faculty, students and stakeholders.

- Since the focus of this case study is only the buildup of teachers' resiliency of island teachers, it is therefore recommended to conduct a phenomenological study exploring lifeworld of those teachers commissioned in the islands, especially those who have no prior experiences of living in the said places.

\section{References}

[1] Aguilar, E. (2011). How teachers can build Emotional Resilience. Retrieved from http://www.edwee.org.

[2] Baliad, H. (2017). Teacher Commitment and Teaching Efficacy of Elementary School Teachers in Bangoy District ; https://www.academia.edu/28732420/ 
[3] Bandura, A. (1997). Self-efficacy: The exercise of control. New York, NY: W. H. Freeman.

[4] Bayrak, C. (2004). Öğretmenlik Mesleğine Giriş. Ö. Demirel ve Z. Kaya (Editörler). (Beşinci Bask1). Ankara: PegemA Yayıncılik

[5] Beltman, S. \& Wosnitza, M. (2008). "You are getting too old, find a man and marry": Social aspects of motivation to choose teacher education. Australian Journal of Educational and Developmental Psychology, 8, 49-63.

[6] Estaji, M. and Rahimi, E. (2014). Examining the ESP Teachers' Perception of Resilience. Retrieved from http://core.ac.uk/download pdf/B1129705edf.

[7] Gu, Q. and Day C. (2007). Teachers resilience: A necessary condition for effectiveness. Retrieved from www.elsevier.com.

[8] Henderson, N., \& Milstein, M. (2003). Resiliency in schools: Making it happen for students and educators. Thousand Oaks, California: Corwin Press

[9] Hunt, B. C. (). Teacher Effectiveness: A review of the International Literature and Its Relevance for Improving Education. Retrieved from achieve. the dialogue. Org.

[10] Kadyschuk, R. Teacher. () Commitment: A Study of organizational commitment, and union commitment of teachers in Public School. Retrieved from https://www.collectionscanada.gc.ca.

[11] Lawreance, A.S. \& Deepa, T. Teacher Commitment in promoting Education. https://www.academic.gc.ca

[12] Mansfield, C. F., Beltman,S., Broadley, T., \& Weatherby---Fell, N. (2016). Building resilience in teacher education: An evidenced informed framework. Teaching and Teacher Education, 54, 77 --87. doi: 10.1016/j.tate.2015.11.016.

[13] Merc, A., Gonca, S. (2015). Classroom Management Problems and Coping Strategies of Turkish Student EFL Teachers. Turkish Online Journal of Qualitative Inquiry. 6. 10. 17569/tojqi.41736.

[14] Reich, W., Zautra, A. J., \& Hall, J.S. (Eds.). (2010). Handbook of adult resilience. New York, NY: Guilford.

[15] Tschannen-Moran, M. \& McMaster, P. (2009). Sources of self-efficacy: Four professional development formats and their relationship to self-efficacy and implementation of a new teaching strategy. The Elementary School Journal, 110, 228-245.

[16] Tschannen-Moran, M., \& Woolfolk Hoy, A. (2012). The differential antecedents of self-efficacy beliefs of novice and experienced teachers. Teaching and Teacher Education, 23, 944-956.

[17] Waller, M. (2001). Resilience in ecosystematic context: Evolution of the contecept. American Journal of Orthopsychiatry, 7(3), 290-297.

[18] Wa-Mbaleka, S. (2016). Handouts on Qualitative Research (Seminar Handouts). Eastern Samar State University Salcedo Campus, Eastern Samar, Philippines.

*Corresponding author.

E-mail address: tvglacaba@yahoo.com.ph/alvinlacaba73@yahoo.com/junjiecaliwan@yahoo.com.ph 